\title{
Changes in cortical negative potential associated with local anesthetization of apex of tooth root
}

\author{
Atsushi Uchida*1, Masafumi Yoshida*2 and Taketo Yamaguchi*3 \\ *1 Department of Dentistry, Saitama Prefecture Ranzango, Saitama 355-0201, JAPAN \\ *2 Department of Pediatric Dentistry, Nihon University School of Dentistry \\ 1-8-13, Kanda-Surugadai, Chiyoda-ku, Tokyo 101-8310, JAPAN \\ *3 Department of Dentistry, Saitama Prefecture Kaikoen, Saitama 366-0081, JAPAN
}

\begin{abstract}
To determine whether cortical negative potential (hereafter referred to as CNP), which was recorded from the scalp (sites: T3, CZ and T4), preceding the right-side chewing is affected by input from the periodontal membrane, the CNP and pattern of the appearance of masseter electric discharge before the anesthetization of the apex of the tooth root and those after the anesthetization were compared.

1) CNP preceding the right-side chewing appeared at T4 early both before and after the anesthetization and showed a maximum amplitude immediately before masseter electric discharge. CNP duration and amplitude increased after the anesthetization as compared with those before the anesthetization.

2) The initial increase in electromyogram associated with chewing became sharper after the anesthetization than before the anesthetization.

From these findings, that the cerebral cortex is in a preparatory state at an early stage when the sensation in the periodontal membrane on the chewing side is blocked, and that, as a consequence, strong chewing is produced.
\end{abstract}

Key words

Cerebral negative potential,

Chewing motion,

Electromyogram,

Local anesthetization,

Periodontal membrane

\section{Introduction}

The cortical negative potential (hereafter referred to as CNP) recorded from the human scalp is also referred to as movement-related cortical potential (hereafter referred to as MRCP) ${ }^{1-17)}$, and reflects the preparatory state of the brain for movement. On the basis of the distribution of its appearance, MRCP in the cerebral cortex was reported to be related to the limb movement and body area localization ${ }^{4,7}$. Many reports on MRCP are related to its relationships with the upper and lower limb movements ${ }^{5-17}$. There are few reports on the closing movement of the jaw

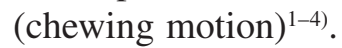

Vaughan et al. $^{4)}$ also determined CNP during the chewing motion as MRCP because it is related to movement. They reported that this MRCP is

Received on July 7, 2005

Accepted on January 18, 2006 recorded from an outside lateral area corresponding to hand motor function. However, they observed CNP only in one hemisphere, and did not investigate the distribution of CNP appearance in the entire brain in detail.

Nakajima et al. ${ }^{1,2)}$ compared the distributions of CNP appearance ipsilateral and contralateral to the chewing side and reported that the ipsilateral distribution of CNP appearance is predominant. Tanaka et al. ${ }^{3)}$ recorded the topography of CNP from electrodes placed at 12 sites of the scalp and reported that $\mathrm{CNP}$ for the chewing motion is localized to the temporal area ipsilateral to the chewing side 50 to $70 \mathrm{~ms}$ before the start of masseter electric discharge.

On the other hand, the chewing motion functions to crush food voluntarily ${ }^{18)}$. It is easily conceivable therefore that one's sensation of the periodontal membrane has a great effect on one's occlusion force and chewing force depending on one's dental 
condition and food characteristics ${ }^{19}$.

To clarify the effects of the input from the periodontal membrane to the cerebral cortex on the CNP appearance preceding the chewing motion, we investigated changes in CNP appearance and the initial increase in masseter electric discharge with the apex of the tooth root under anesthetization.

\section{Subjects and Methods}

\section{Subjects of study}

The study subjects were 14 healthy adults (6 males; average age, $32.0 \pm 6.0$ years old and 8 females; average age, $29.0 \pm 4.6$ years old) with individual normal dental articulation, who had no history of neuropathy, and who had no stomatognathic function or periodontal tissue abnormalities. All the subjects showed right-side habitual mastication. All the subjects were chosen on the basis of the following criteria: the right maxillary or mandibular region has no tooth defects and the filling, if any, is localized to the pit and fissure. The subjects sat relaxed on an armchair with the facial horizontal (FH) plane nearly perpendicular to the floor and chewed while gazing at an index positioned $1.5 \mathrm{~m}$ in front of them at eye level (Figure 1).

Prior to the study, the details of the study were fully explained to the subjects themselves, guardians (parents) and caretakers, and their consent was obtained. Approval for the study was given by the President of Ranzango., the Director of Ranzango Hospital and the Manager of the Dental Department.

\section{Measurement of CNP}

Electroencephalographic recording from the left temporal area (T3), middle-central area (CZ), right temporal area (T4), and bilateral ear lobes was performed using unipolar lead in accordance with the International Potential Method (10-20 methods). Electroophthalmograms were recorded to examine the potential generated by the winking motion, which were also present in electroencephalograms. Electroencephalograms containing this potential were excluded from data analysis. Electromyocardiograms of the masseter were recorded from the skin at the center of the masseter shallow area using bipolar lead. Silver - silver hydrochloride surface electrodes were used to record electroencephalograms, electroophthalmograms and electromyocardiograms.

The amplification and recording of electroencephalograms, electroophthalmograms and electro-

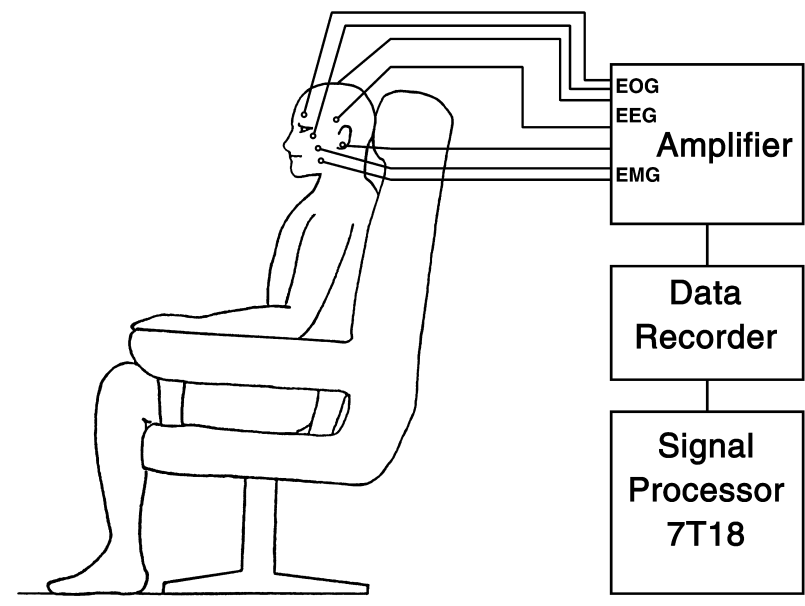

Fig. 1 Experiment block diagram

EOG: electro-oculogram; EEG: electroence-phalogram; EMG: electromyogram

myograms were carried out using the Polygraph 362 system and Rectigraph 8K (NEC San-ei Instruments). These data were simultaneously recorded on 14-ch, Data Recorder XR 510 (TEAC Inc.). The time constants for electroencephalography and electroophthalmography were determined as $1.5 \mathrm{~s}$. The time constant for electromyography was determined as $0.01 \mathrm{~s}$. The electromyograms of the masseter on the chewing motion side were subjected to full-wave integral rectification and the result was determined as a CNP trigger pulse. CNP was obtained by 50 times of signal averaging of electroencephalograms, electroophthalmograms and electromyograms for $2 \mathrm{~s}$ before and for $1 \mathrm{~s}$ after the start of masseter electric discharge, using Signal Processor 7T18 (NEC San-ei Instruments).

\section{Measurement conditions}

The specified motion was the habitual mastication side or the right-side chewing. The subjects chewed quickly once every 3 to $5 \mathrm{~s}$ at their own pace, and they were instructed not to move their tongue during chewing. After they had practiced chewing about ten times before the start of the experiments, the subjects carried out two or three trials, each of which consists of chewing 50 times.

To ensure that all the subjects performed the right-side chewing at a fixed mouth opening, a resin block was used. Hirabayashi et $a .^{20)}$ reported that the maximum articulation force is generated at a mean mouth opening of $10.4 \mathrm{~mm}$ at the incisor teeth. On the basis of this report, we prepared resin blocks 


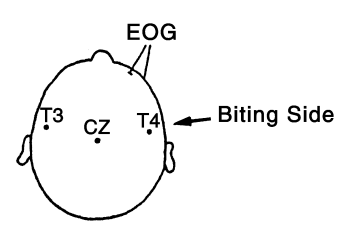

A

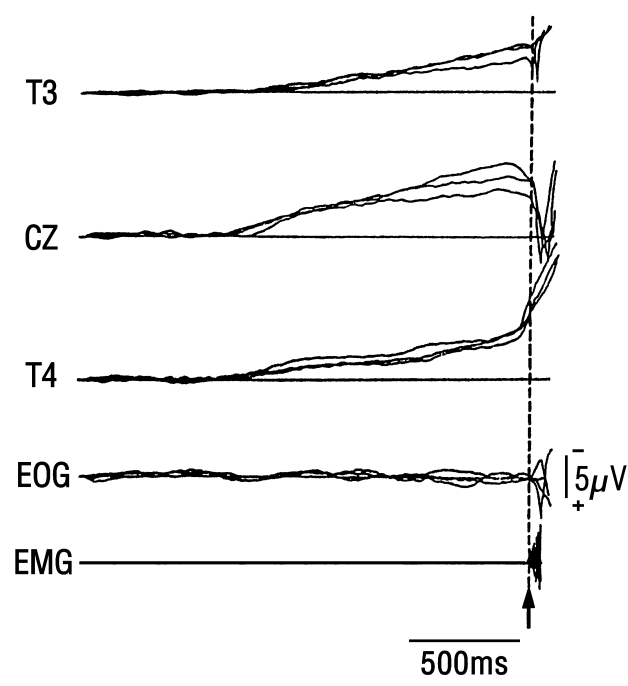

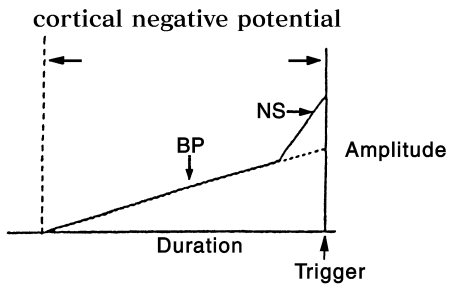

B

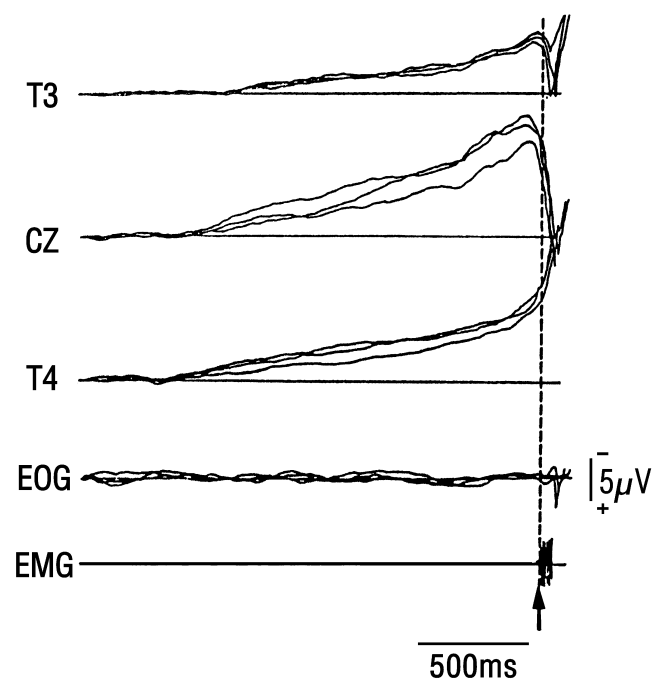

Fig. 2 Pattern of appearance of CNP associated with right-side chewing before and after anesthetization A: before anesthetization; B: after anesthetization; T3: left temporal area; CZ: midline-central area; T4: right temporal area; EOG: electro-oculogram; EMG: electromyogram; BP: Bereitschaftspotential; NS: negative slope

for fixing the mouth opening (interincisal distance) of $10 \mathrm{~mm}$ at the incisor teeth, the articulation load area of which covered the area from the second premolar teeth to the third tooth of the second molar teeth of the right mandible ${ }^{21}$. The method of preparing the resin blocks was as follows. The impressions of the subjects' upper and lower jaws were obtained using an alginic acid impression material. These impressions were mounted on a Whip-Mix articulator in a centric jaw relation. A resin block was then formed on the articulator using instant copolymerization resin.

To block pressoreceptors in the periodontal membrane of the habitual mastication side or the right side, the periodontal membrane was anesthetized by applying $20 \%$ ethyl aminobenzoate ointment (Bezoccaine Gel, Fukuchi Pharmaceutical Co., Ltd.), a dental surface anesthetic, to the right apexes of the roots of the first molar teeth of the right upper and lower jaws, followed by the administration of $1.8 \mathrm{ml}$ of a dental local anesthetic, $2 \%$ lidocaine hydrochloride (Indrol, Showa Yakuhin Kako Co.,
Ltd.). Regarding the depth of anesthetization, the anesthetics were administered according to the method described by Yamakura ${ }^{22)}$, Tanaka et al. ${ }^{23)}$ and Tanaka ${ }^{24)}$, although a correlation between the disappearance of pressure sensation and voluntary movement is yet to be clarified.

\section{Measurement of CNP factors}

The CNP factors measured during chewing were CNP duration and maximum potential amplitude. CNP has two components: the Bereitschafts potential (hereafter referred as BP) and negative slope (hereafter referred as NS) that appears after BP (Figure 2), in accordance with the classification by Nakajima et al. ${ }^{2)}$ CNP duration was defined as follows: by setting the mean electroencephalogram before the start of masseter electric discharge as the reference potential (baseline), CNP duration is defined as the time difference between the appearance of scalp surface negative potential from the baseline and the start of electric discharge from the right masseter. The maximum CNP amplitude at 


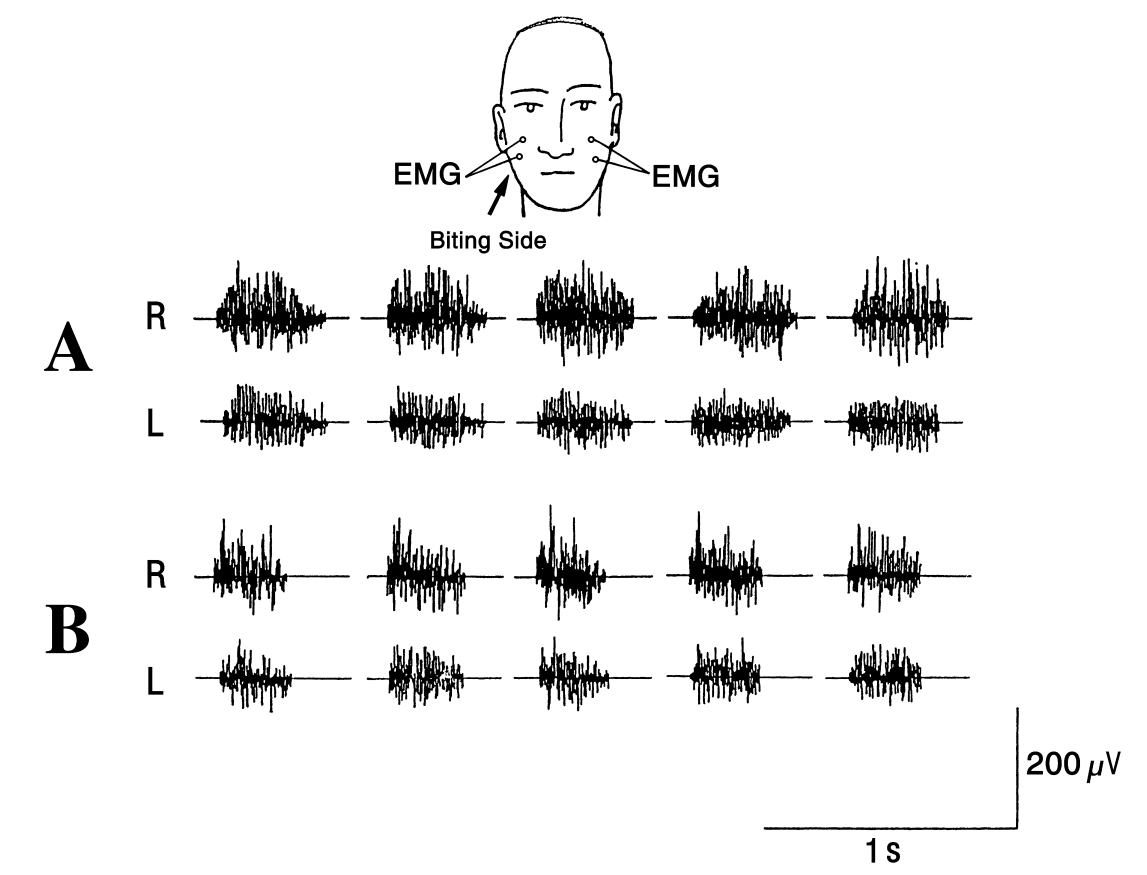

Fig. 3 Right and left masseter electric discharges associated with right-side chewing before and after anesthetization

A: before anesthetization; B: after anesthetization; R: right; L: left

each recording site was obtained by calculating the peaks of BP and NS generated from the baseline to the start of electric discharge from the right masseter, according to the method of Nakajima et $a{ }^{2)}$ CNP duration and maximum CNP amplitude were subjected to Wilcoxon's $t$-test to determine the significance of difference.

\section{Statistical analysis}

Cerebral cortex excitation continues during masseter electric discharge, and the electromyogram of the temporal muscle is mixed with the electroencephalogram associated with the chewing motion. It is impossible therefore to investigate the relationship between all the electromyograms and $\mathrm{CNP}^{1-3)}$. The initial increase in initial masseter electric discharge reflects CNP amplitude ${ }^{15)}$. Hence, to determine how CNP appearance is related to masseter electric discharge, in this study, we compared the initial period (peak values and intermediate values) of masseter electric discharge (full-wave rectification integral) before and after the anesthetization. In the statistical analysis of these data, the intermediate values between the start of masseter electric discharge and the peak values were tested using a paired $t$-test.

\section{Results}

Masseter activities before and after anesthetization

Typical examples of electric discharge from the right and left masseters associated with the right-side chewing (quick and short) before and after the anesthetization are shown in Figure 3. In the case of the right-side chewing before (A) and after (B) the anesthetization, the electric discharge from the right masseter was always more marked than that from the left masseter. A comparison of the electric discharges from the right and left masseters before and after the anesthetization showed that both the durations of electric discharges from the right and left masseters tended to decrease after the anesthetization as compared with those before the anesthetization.

\section{Patterns of CNP appearance associated with chewing motion before and after local anesthetization}

Figure 2 shows typical patterns of CNP appearance before and after the anesthetization. The waveforms were recorded from the same subject on three different days. When the subject made the right-side 
Table 1 CNP durations associated with right-side chewing before and after anesthetization

\begin{tabular}{|c|c|c|c|c|c|c|}
\hline \multirow{2}{*}{ Sub. } & \multicolumn{2}{|c|}{ T3 } & \multicolumn{2}{|c|}{$\mathrm{CZ}$} & \multicolumn{2}{|c|}{$\mathrm{T} 4$} \\
\hline & A & B & A & B & A & B \\
\hline 1 & 1.12 & 1.14 & 0.96 & 1.25 & 1.40 & 1.73 \\
\hline 2 & 1.42 & 1.24 & 1.22 & 1.33 & 1.41 & 1.54 \\
\hline 3 & 1.36 & 1.44 & 1.25 & 1.23 & 1.45 & 1.68 \\
\hline 4 & 1.36 & 1.32 & 0.00 & 1.48 & 1.45 & 1.59 \\
\hline 5 & 0.99 & 1.21 & 1.03 & 1.08 & 1.13 & 1.29 \\
\hline 6 & 1.26 & 1.37 & 1.25 & 1.60 & 1.38 & 1.61 \\
\hline 7 & 0.00 & 1.52 & 0.00 & 1.43 & 1.07 & 1.72 \\
\hline 8 & 0.00 & 1.45 & 1.08 & 1.40 & 1.11 & 1.52 \\
\hline 9 & 0.00 & 1.34 & 0.98 & 1.13 & 1.07 & 1.46 \\
\hline 10 & 0.93 & 1.17 & 0.00 & 1.45 & 1.36 & 1.48 \\
\hline 11 & 0.93 & 1.53 & 0.91 & 1.19 & 1.20 & 1.58 \\
\hline 12 & 1.04 & 1.04 & 0.93 & 1.09 & 1.38 & 1.46 \\
\hline 13 & 0.92 & 1.16 & 0.93 & 1.27 & 0.97 & 1.33 \\
\hline 14 & 0.95 & 1.48 & 0.92 & 1.46 & 1.20 & 1.61 \\
\hline MEAN & 0.88 & 1.32 & 0.82 & 1.31 & 1.26 & 1.54 \\
\hline S.D. & 0.51 & 0.16 & 0.46 & 0.16 & 0.17 & 0.13 \\
\hline $\begin{array}{c}\text { Wilcoxon } \\
t \text {-test }\end{array}$ & & & & & & \\
\hline
\end{tabular}

Results of statistical analysis of significant difference between CNP durations at recording sites before (A) and after (B) anesthetization

chewing motion, CNP appeared at $\mathrm{T} 3, \mathrm{CZ}$ and $\mathrm{T} 4$, and gradually increased until the start of masseter electric discharge (Figure 2-A). CNP durations were $1.29 \pm 0.03 \mathrm{~s}$ at T3, $1.35 \pm 0.09 \mathrm{~s}$ at $\mathrm{CZ}$, and $1.39 \pm$ $0.03 \mathrm{~s}$ at $\mathrm{T} 4$. BP appeared the earliest at $\mathrm{T} 4$ or on the side ipsilateral to the chewing side. A marked $\mathrm{BP}$ amplitude was observed early at $\mathrm{CZ}$, whereas BP appeared slightly late in the right and left temporal areas, and thereafter increased gradually. NS, appearing immediately before masseter electric discharge, was observed only at T4 on the chewing side, and a maximum NS amplitude appeared immediately before masseter electric discharge. The maximum CNP amplitudes at the recording sites were $5.54 \pm 0.46 \mu \mathrm{V}$ as $\mathrm{BP}$ at $\mathrm{T} 3$ and $7.35 \pm 1.47 \mu \mathrm{V}$ as $\mathrm{BP}$ at $\mathrm{CZ}$ and $7.64 \pm 0.58 \mu \mathrm{V}$ as NS at T4.

The typical CNP durations associated with the chewing motion after the anesthetization were 1.41 $\pm 0.04 \mathrm{~s}$ at $\mathrm{T} 3,1.58 \pm 0.04 \mathrm{~s}$ at $\mathrm{CZ}$, and $1.60 \pm 0.02 \mathrm{~s}$ at T4 (Figure 2-B). BP appeared the earliest at T4. A marked BP amplitude was observed early at CZ, whereas BP also appeared slightly later in the right and left temporal areas and thereafter increased gradually. NS was observed at only $\mathrm{T} 4$, and a maximum NS amplitude appeared immediately before masseter electric discharge. The maximum CNP amplitudes at the recording sites were $6.94 \pm 0.48 \mu \mathrm{V}$ and $13.26 \pm 1.91 \mu \mathrm{V}$ as $\mathrm{BP}$ at $\mathrm{T} 3$ and $\mathrm{CZ}$, respectively, and $10.05 \pm 0.19 \mu \mathrm{V}$ as NS at $\mathrm{T} 4$. The comparison of CNP durations and maximum CNP amplitudes before and after the anesthetization showed that both the CNP duration and maximum CNP amplitude markedly increased after the anesthetization.

Tables 1 and 2 show the CNP durations and maximum CNP amplitudes, respectively, at T3, CZ and $\mathrm{T} 4$ before and after the anesthetization in the 14 subjects. The CNP durations at T3, CZ and T4 before the anesthetization were $0.88 \pm 0.51 \mathrm{~s}$ at $\mathrm{T} 3,0.82 \pm 0.46 \mathrm{~s}$ at $\mathrm{CZ}$, and $1.26 \pm 0.17 \mathrm{~s}$ at $\mathrm{T} 4$ respectively. Among the CNPs, CNP at T4 appeared the earliest. The CNP durations at T3, CZ and $\mathrm{T} 4$ after the anesthetization were $1.32 \pm 0.16 \mathrm{~s}$ at $\mathrm{T} 3,1.31 \pm 0.16 \mathrm{~s}$ at $\mathrm{CZ}$, and $1.54 \pm 0.13 \mathrm{~s}$ at $\mathrm{T} 4$ respectively. CNP at T4 appeared the earliest. The comparison of CNP durations before and after the anesthetization showed that the CNP duration significantly increased at all the recording sites after 
Table 2 Maximum CNP amplitudes associated with right-side chewing before and after anesthetization

\begin{tabular}{|c|c|c|c|c|c|c|}
\hline \multirow{2}{*}{ Sub. } & \multicolumn{2}{|c|}{ T3 } & \multicolumn{2}{|c|}{$\mathrm{CZ}$} & \multicolumn{2}{|c|}{$\mathrm{T} 4$} \\
\hline & A & B & A & B & A & B \\
\hline 1 & 3.19 & 4.50 & 3.70 & 5.01 & $\Delta 6.09$ & А 9.93 \\
\hline 2 & 3.58 & 3.96 & 6.85 & 10.07 & 7.54 & 7.92 \\
\hline 3 & 3.50 & $\Delta 5.22$ & 3.53 & 4.27 & $\Delta 6.92$ & $\boldsymbol{\Delta} 10.42$ \\
\hline 4 & 3.01 & 4.63 & 0.00 & 5.84 & $\mathbf{\Delta} 4.19$ & А 5.17 \\
\hline 5 & 2.30 & 4.08 & 4.59 & 6.67 & 2.70 & 4.10 \\
\hline 6 & 5.06 & 6.41 & 5.88 & 15.05 & $\mathbf{\Delta} 7.04$ & $\Delta 10.52$ \\
\hline 7 & 0.00 & 2.44 & 0.00 & 4.36 & 5.10 & 5.23 \\
\hline 8 & 0.00 & 3.49 & 3.79 & 4.19 & $\Delta 4.67$ & А 6.52 \\
\hline 9 & 0.00 & 4.80 & 3.57 & 6.04 & 5.21 & 7.20 \\
\hline 10 & 3.23 & 4.35 & 0.00 & 4.35 & $\Delta 4.75$ & - 7.44 \\
\hline 11 & 3.88 & А 8.96 & 3.34 & 5.30 & $\mathbf{\Delta} 7.82$ & $\Delta 10.60$ \\
\hline 12 & 2.32 & 2.83 & 3.61 & 3.90 & $\Delta 5.33$ & А 6.77 \\
\hline 13 & 7.21 & А 13.83 & 4.28 & 5.44 & $\Delta 8.18$ & $\Delta 16.19$ \\
\hline 14 & $\Delta 5.23$ & $\Delta 11.98$ & 5.33 & 9.61 & $\Delta 9.09$ & $\Delta 13.60$ \\
\hline MEAN & 3.04 & 5.79 & 3.46 & 6.44 & 6.05 & 8.69 \\
\hline S.D. & 2.08 & 3.33 & 2.13 & 3.13 & 1.78 & 3.40 \\
\hline $\begin{array}{c}\text { Wilcoxon } \\
t \text {-test }\end{array}$ & \multicolumn{2}{|c|}{ ** } & \multicolumn{2}{|c|}{$* *$} & \multicolumn{2}{|c|}{$* *$} \\
\hline
\end{tabular}

(A)

\begin{tabular}{cccc}
\hline & $\mathrm{T} 3$ & $\mathrm{CZ}$ & $\mathrm{T} 4$ \\
\hline $\mathrm{T} 3$ & & - & $* *$ \\
$\mathrm{CZ}$ & - & & $* *$ \\
$\mathrm{~T} 4$ & $* *$ & $* *$ & \\
\hline
\end{tabular}

\begin{tabular}{cccc}
\hline & $\mathrm{T} 3$ & $\mathrm{CZ}$ & $\mathrm{T} 4$ \\
\hline $\mathrm{T} 3$ & & - & $* *$ \\
$\mathrm{CZ}$ & - & & $*$ \\
$\mathrm{~T} 4$ & $* *$ & $*$ & \\
\hline Wilcoxon $t$-test & $*: P<0.05$ \\
& $* *: P<0.01$ \\
& $-:$ not significant
\end{tabular}

Results of statistical analysis of significant difference between maximum CNP amplitudes at recording sites before (A) and after (B) anesthetization

$\boldsymbol{\Delta}$ in the table denotes NS and the other symbols denote BP.

the anesthetization (Table 1).

The maximum CNP amplitudes at $\mathrm{T} 3, \mathrm{CZ}$ and $\mathrm{T} 4$ before the anesthetization were $3.04 \pm 2.08 \mu \mathrm{V}$, $3.46 \pm 2.13 \mu \mathrm{V}$ and $6.05 \pm 1.78 \mu \mathrm{V}$, respectively. The largest maximum CNP amplitude after the anesthetization was observed at T4. The maximum CNP amplitudes at $\mathrm{T} 3, \mathrm{CZ}$ and $\mathrm{T} 4$ after the anesthetization were $5.79 \pm 3.33 \mu \mathrm{V}, 6.44 \pm 3.13 \mu \mathrm{V}$ and $8.69 \pm$ $3.40 \mu \mathrm{V}$, respectively. The largest maximum CNP amplitude after the anesthetization was observed at T4, similar to the finding before the anesthetization. The comparison of the maximum CNP amplitudes before and after anesthetization showed that the maximum CNP amplitude increased significantly after the anesthetization at all the recording sites (Table 2). The rates of CNP appearance before the anesthetization were $100 \%(14 / 14)$ at T4 and 79\% $(11 / 14)$ at $\mathrm{CZ}$ and T3. The rates of CNP appearance after anesthetization were $100 \%(14 / 14)$ at all the recording sites. The rates of NS appearance before the anesthetization were $71 \%(10 / 14)$ at $\mathrm{T} 4,7 \%$ $(1 / 14)$ at $\mathrm{T} 3$, and $0 \%(0 / 14)$ at $\mathrm{CZ}$. The rates of NS appearance after the anesthetization were $71 \%$
$(10 / 14)$ at $\mathrm{T} 4,29 \%(4 / 14)$ at $\mathrm{T} 3$, and $0 \%(0 / 14)$ at $\mathrm{CZ}$.

\section{Patterns of appearance of initial masseter electric discharges before and after local anesthetization}

Figure 4 shows typical results in which the initial appearances of the electric discharges from the right and left masseters recorded in association with the chewing motion before and after the local anesthetization were compared and superposed three times. The waveforms were superposed at the point of the initial increase from the baseline as the reference. The comparison of the initial increases in right masseter electric discharges before and after the local anesthetization showed that the rising slope of the electric discharge after the anesthetization became sharper than that before the anesthetization. The comparison of the initial increases in left masseter electric discharges before and after the local anesthetization showed that the rising slope of the electric discharge after the anesthetization became slightly sharper than that before the anesthetization. The times for right masseter electric 


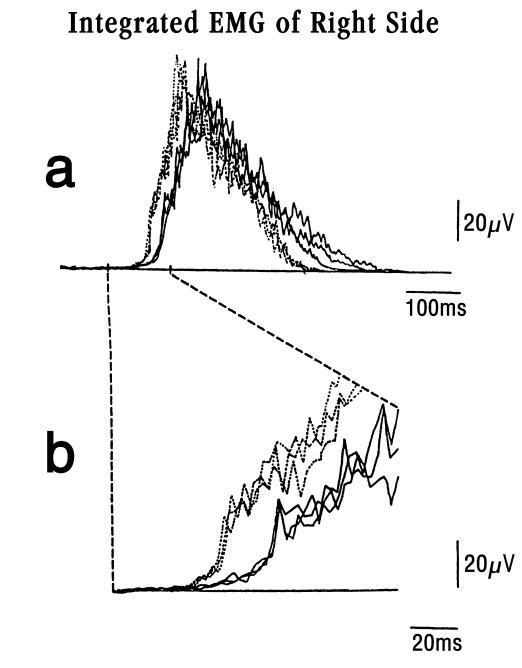

Integrated EMG of Left Side

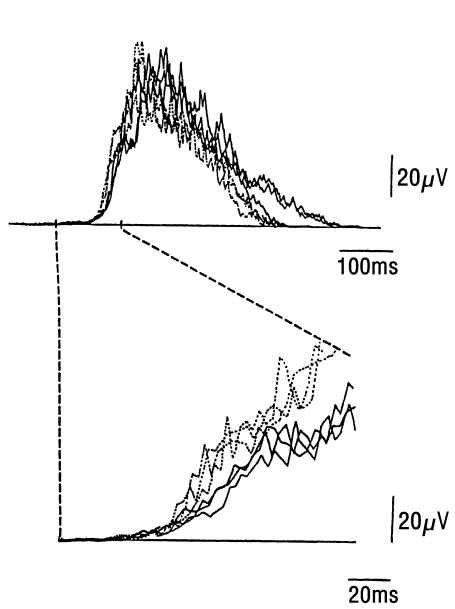

Fig. 4 Pattern of initial appearance of masseter electric discharges associated with strong and weak chewing before and after anesthetization

a: Superposition of three masseter electric discharge waveforms associated with chewing subjected to full-wave rectification integration

b: Expansion of initial component of ' $a$ '

(Solid line: before anesthetization; Dotted line: after anesthetization)

discharge to reach the peak at all the recording sites were $150.00 \pm 9.00 \mathrm{~ms}$ and $100.00 \pm 9.17 \mathrm{~ms}$ before and after the anesthetization, respectively. The times for left masseter electric discharge to reach the peak were $152.00 \pm 7.55 \mathrm{~ms}$ before the anesthetization and $123.00 \pm 10.82 \mathrm{~ms}$ after the anesthetization. Both the right and left masseter electric discharges tended to reach their peaks earlier after the anesthetization than before the anesthetization. The amplitudes at the mean intermediate point $(70 \mathrm{~ms})$ of the time for right masseter electric discharge to reach the peak were $38.18 \pm 3.55 \mu \mathrm{V}$ before the anesthetization and $65.71 \pm 6.98 \mu \mathrm{V}$ after the anesthetization. The amplitudes at the mean intermediate point $(70 \mathrm{~ms})$ of the time for left masseter electric discharge to reach the peak were $31.87 \pm 2.33 \mu \mathrm{V}$ before the anesthetization and $49.11 \pm 4.70 \mu \mathrm{V}$ after the anesthetization. The increases in right masseter electric discharges were consistently sharper than those in left masseter electric discharges before and after the anesthetization.

Table 3 shows the initial amplitudes of masseter electric discharges (mean intermediate point to the peak) associated with the chewing motion in the 14 subjects. This mean intermediate point was determined to be approximately $70 \mathrm{~ms}$. The amplitudes of the right and left masseter electric discharges before the anesthetization were $59.08 \pm 31.21 \mu \mathrm{V}$
Table 3 Initial amplitudes of masseter electric discharges associated with chewing before and after anesthetization

\begin{tabular}{|c|c|c|c|c|}
\hline \multirow{2}{*}{ Sub. } & \multicolumn{2}{|c|}{ RIGHT } & \multicolumn{2}{|c|}{ LEFT } \\
\hline & A & B & A & B \\
\hline 1 & 52.24 & 117.91 & 37.16 & 70.94 \\
\hline 2 & 5.45 & 88.98 & 36.67 & 57.07 \\
\hline 3 & 38.07 & 42.72 & 29.79 & 38.90 \\
\hline 4 & 89.55 & 161.13 & 79.21 & 141.52 \\
\hline 5 & 39.36 & 69.63 & 31.69 & 64.36 \\
\hline 6 & 37.51 & 60.92 & 22.73 & 50.44 \\
\hline 7 & 29.52 & 42.04 & 25.03 & 32.73 \\
\hline 8 & 47.87 & 54.31 & 40.91 & 50.46 \\
\hline 9 & 58.11 & 94.97 & 39.76 & 91.41 \\
\hline 10 & 23.00 & 49.22 & 22.72 & 41.33 \\
\hline 11 & 40.28 & 79.66 & 23.22 & 29.86 \\
\hline 12 & 130.90 & 192.53 & 112.05 & 140.96 \\
\hline 13 & 88.07 & 102.47 & 67.42 & 101.70 \\
\hline 14 & 100.22 & 114.43 & 98.53 & 108.32 \\
\hline MEAN & 59.08 & 90.78 & 47.64 & 72.86 \\
\hline \multirow[t]{2}{*}{ S.D. } & 31.21 & 44.69 & 29.59 & 37.95 \\
\hline & RIGHT-A & RIGHT-B & LEFT-A & LEFT-B \\
\hline RIGHT-A & & $* *$ & $* *$ & \\
\hline RIGHT-B & $* *$ & & & $* *$ \\
\hline LEFT-A & $* *$ & & & $* *$ \\
\hline LEFT-B & & $* *$ & $* *$ & \\
\hline
\end{tabular}

A: before anesthetization; B: after anesthetization paired $t$-test $* *: P<0.01$ 
and $47.64 \pm 29.59 \mu \mathrm{V}$, respectively. The former was significantly larger. The amplitudes of the right and left masseter electric discharges after the anesthetization were $90.78 \pm 44.69 \mu \mathrm{V}$ and $72.86 \pm$ $37.95 \mu \mathrm{V}$, respectively. The former was significantly larger. The comparison of the amplitudes of right masseter electric discharges before and after the anesthetization showed that the amplitude after the anesthetization $(90.78 \pm 44.69 \mu \mathrm{V})$ was significantly larger than that before anesthetization (59.08 \pm $31.21 \mu \mathrm{V})$. The comparison of the amplitudes of left masseter electric discharges before and after the anesthetization also showed similar results; the amplitude after the anesthetization (72.86 \pm $37.95 \mu \mathrm{V}$ ) was significantly larger than that before the anesthetization $(47.64 \pm 29.59 \mu \mathrm{V})$.

\section{Discussion}

\section{Patterns of CNP appearances before and after anesthetization}

CNP was recorded in the bilateral temporal areas (T3 and T4) and the midline central area (CZ) from 1 to $2 \mathrm{~s}$ preceding a voluntary chewing motion. CNP showing the largest amplitude appeared in the temporal area on the chewing side (T4). These findings were in agreement with those reported by Nakajima et al. ${ }^{1,2)}$ and Tanaka et al. ${ }^{3)}$ Moreover, Shibasaki et al. ${ }^{10,11)}$ referred to CNP as movementrelated cortical potential and divided it into two components, BP and NS. NS is related to finger movement and is localized to the center or the contralateral side (of the cerebral cortex). NS has therefore been considered to be generated in an area directly related to finger movement ${ }^{10,11)}$.

Evarts ${ }^{25)}$ reported on the basis of records from monkey brains obtained using microelectrodes that pyramidal cells became active from 60 to $100 \mathrm{~ms}$ before the start of masseter electric discharge during wrist movement. Nakajima et al. ${ }^{2)}$ considered that because NS appearance in the temporal area on the side ipsilateral to the chewing side was observed from 70 to $80 \mathrm{~ms}$ before the start of masseter electric discharge, NS reflected neuron activity in the area directly related to the chewing motion. It was also identified that NS amplitude and the rate of NS appearance were ipsilaterally dominant ${ }^{2}$. In the present study, the ipsilaterally dominant appearance of NS was observed both before and after the anesthetization. These findings were similar to those reported by Nakajima et al. ${ }^{2)}$ In addition, NS increased markedly after the anesthetization as compared with that before the anesthetization. This suggests that neuron activity on the side ipsilateral to the chewing area (T4) further increased in association with the chewing motion after the anesthetization.

Shibasaki et al. ${ }^{10,11)}$ considered that BP reflects the preparatory state of the cerebral cortex for extensive voluntary movement. In the present study, BP appeared earlier with a long BP duration and an increased amplitude after the anesthetization than before the anesthetization. BP was not observed at $\mathrm{T} 3$ or $\mathrm{CZ}$ on the contralateral side before the anesthetization in some subjects. However, BP in these subjects was also detected at both $\mathrm{T} 3$ and $\mathrm{CZ}$ after the anesthetization. The appearance of $\mathrm{BP}$ from 1 or $2 \mathrm{~s}$ before the start of masseter electric discharge could not be explained by only the activity of pyramidal cells. As a factor underlying this long $\mathrm{BP}$ duration, it is assumed that BP appears after traveling from the cerebellum via the thalamus to be projected to the cortex. This assumption is supported by a report by Sasaki et al. ${ }^{26)}$ that during hand movement in monkeys, BP begins to appear 1 or $2 \mathrm{~s}$ before the start of masseter electric discharge and that the cerebellum is involved in BP appearance, as shown by a marked decrease in BP following the extirpation of the cerebellum. A study also showed a marked decrease in BP in patients with cerebella ataxia or thalamus impairment ${ }^{12)}$.

Regarding BP measurement at $\mathrm{CZ}, \mathrm{CZ}$ corresponds to the supplementary motor area ${ }^{27-29)}$ that sends strong transcortical projection to the motor area $^{27)}$ and thus appears to supplement cell activity in the motor area. At least part of the increased BP amplitude on the contralateral side of the temporal area (T3) is considered to have been induced by the cortex-to-cortex projection from the ipsilateral side (T4) to the contralateral side (T3).

It is generally considered that voluntary movement, which is formed by past experience and learning, proceeds smoothly and orderly based on a program stored in the cerebellum and cerebral basal ganglia ${ }^{30)}$. Tanaka ${ }^{24)}$ considered that in his experiment, the periodontal membrane is blocked, because the sensation-of-pressure threshold increases threefold or more following the administration of an anesthetic to the apex of the tooth root. Taking also these reports into consideration, it is considered in the present study that the sensation input from the periodontal membrane blocked by 
local anesthetization prevented the entry of the input required for the movement program for the chewing motion and proper control for movement execution, resulting in a large CNP (BP and NS).

\section{Patterns of masseter electric discharges before and after anesthetization}

The comparison of total electric discharges from the masseter during chewing on the articulation and nonarticulation sides shows a greater electric discharge on the former than on the latter ${ }^{1-3,31)}$. The present study also showed that the electric discharge from the right side or articulation side was markedly greater than that from the left side or nonarticulation side regardless of anesthetization. The sharp initial increase in masseter electric discharge after the anesthetization (Figure 4) seems attributable to the inhibition of initial electric discharge during chewing by inputs in areas adjacent to the injection site, particularly the area from the periodontal membrane to the cerebral cortex, although this is not conclusive in the absence of the placebo group in this study.

The subjects were instructed to chew quickly in the present study. The total masseter electric discharge duration after the anesthetization decreased as compared with that before the anesthetization. Although Yamashina et al. ${ }^{32}$ did not assess the initial components of masseter electric discharges before and after the anesthetization in the chewing motion in their experiment with the periodontal membrane on the chewing side under anesthetization, they reported that the total masseter electric discharge duration markedly decreases after the anesthetization. This decreased masseter electric discharge duration agreed with our results. CNP is likely mixed with temporal masseter electric discharge generated simultaneously with masseter electric discharge; hence, it is difficult to measure CNP after the generation of masseter electrical discharge. In view of this, the comparison of CNPs was limited only to the initial component of masseter electric discharge in this study. Following the anesthetization of the apex of the tooth root, the initial component of masseter electric discharge and the amplitude at the intermediate point significantly increased. These findings were attributable to the anesthetization of the periodontal membrane, leading to the early appearance of CNP (both BP and NS), subsequently resulting in a sharp increase in the electromyogram with the maximum amplitude.

\section{References}

1) Nakajima, I., Tanaka, Y., Uchida, A., Mori, A. and Sumino, R.: Cerebral potentials preceding voluntary closing. Jpn J EEG EMG 17(4): 387-390, 1989. (in Japanese, English abstract)

2) Nakajima, I., Tanaka, Y., Uchida, A., Sakai, T., Akasaka, M., Mori, A. and Sumino, R.: Cortical potentials associated with voluntary biting movement in humans. Neurosci Res 10: 285-289, 1991.

3) Tanaka, Y., Nakajima, I., Uchida, A., Akasaka, M. and Sumino, R.: Distribution of movement-related cortical potential upon jaw-biting in humans. J Nihon Univ Sch Dent 31: 518-525, 1989. (in Japanese, English abstract)

4) Vaughan, H., Costa, L.D. and Ritter, W.: Topography of the human motor potential. Electroencephalogr Ciin Neurophysiol 25: 1-10, 1968.

5) Deecke, L. and Kornhuber, H.H.: Cerebral potentials and the initiation of voluntary movement. In: Attention, Voluntary Contraction and Event-Related Cerebral Potentials. Progress in Clinical Neurophysiology, Vol. 1. (Desmedt, J.E. ed.) Karger, Basel, 1977, pp.132-150.

6) Deecke, L., Scheid, P. and Kornhuber, H.H.: Distribution of readiness potential, pre-motion positivity, and moter potential of the human cerebral cortex preceding voluntary finger movements. Exp Brain Res 7: 158-168, 1969.

7) Boschert, J. and Deecke, L.: Cerebral potentials preceding voluntary toe, knee and hip movements and their vectors in human precentral gyrus. Brain Res 376: 175-179, 1986

8) Hink, R.F., Deecke, L. and Kornhuber, H.H.: Force uncertainty of voluntary movement and human movement-related potentials. Biol Psychol 16: 197210, 1983.

9) Becker, W. and Kristeva, R.: Cerebral potentials prior to various force deployments. In: Motivation, Motor and Sensory Processes of the Brain. Prog Brain Res, 54. (Kornhuber, H.H. and Deecke, L. eds.) Elsevier, Amsterdam, 1977, pp. 189-194.

10) Shibasaki, H., Barrett, G., Halliday, E. and Hallidy, A.M.: Components of the movement-related cortical potential and their scalp topography. Electroencephalogr Clin Neurophysiol 49: 213-226, 1980.

11) Shibasaki, H., Shima, F. and Kuroiwa, Y.: Clinical studies of the movement-related cortical potential (MP) and the relationship between the dentatorubrothalamic pathway and readiness potential (RP). $J$ Neurol 219: 15-25, 1978.

12) Libet, B., Wright, E.W. and Gleason, C. A.: Readiness potentials preceding unrestricted "spontaneous" vs. pre-planned voluntary acts. Electroencephalogr Clin Neurophysiol 54: 322-335, 1982.

13) Benecke, R., Dick, J.P., Rothwell, J.C., Day, B.L. and Marsden, C.D.: Increase of the Bereitschaftspotential in simultaneous and sequential movements. Neurosci Lett 62: 347-352, 1985. 
14) Barrett, G., Shibasaki, H. and Neshige, R.: Cortical potentials preceding voluntary movement: evidence for three periods of preparation in man. Electroencephalogr Clin Neurophysiol 63: 327-339, 1986.

15) Washimi, Y.: Movement-related cortical potential in normal subjects - The relationship between parameters of movement and readiness potential. Shinsyu Igaku Zasshi 35(6): 793-806, 1987. (in Japanese, English abstract)

16) Kutas, M. and Donchin, E.: Studies of squeezing: handedness, responding hand, response force, and asymmetry of readiness potential. Science 186: 545548, 1974.

17) Kutas, M. and Donchin, E.: The Effect of handedness, the responding hand, and response force on the contralateral dominance of the readiness potential. In: Attention, Voluntary Contraction and Event Related Cerebral Potentials. Progress in Clinical Neurophysiology, Vol. 1. (Desmedt, J.E. ed.) Karger, Basel, 1977, pp. 189-210.

18) Kawamura, Y.: Recent concepts of the physiology of mastication. In: Advances in Oral Biology, Vol. 1. (Staple, P.H. ed.) Academic Press, New York, 1964, pp. 77-109.

19) Boever, J.D., Mccall, W.D., Holden, S. and Ash, M.M.: Functional occlusal forces under anesthesia. J Proste Dent 40: 402-408, 1978.

20) Hirabayashi, T.: A study on biting forces in various maxillomandibular relations. The Journal of the Japan Prosthodontic Society 18: 337-360, 1975. (in Japanese, English abstract)

21) Hirao, F.: A Study on the effects of masticatory muscles activity in various maxillomandibular relations. Shikwa Gakuho 77: 1167-1204, 1977. (in Japanese, English abstract)

22) Yamakura, D.: Studies on the hardness discrimination mechanism of foods. Especially on the significance of periodontal pressoreceptive information and of the amount of biting into foods. Shikwa Gakuho 87: 1295-1346, 1987. (in Japanese, English abstract)
23) Tanaka, Y., Nakajima, I., Uchida, A., Akasaka, M., Mori, A. and Sumino, R.: Somatosensory evoked potentials by mechanical stimulation of tooth in humans. Brain and Nerve 43(2): 163-168, 1991. (in Japanese, English abstract)

24) Tanaka, Y.: Somatosensory evoked potential by pressure stimulation of tooth. Nihon Univ Dent $J$ 66: 762-770, 1992. (in Japanese, English abstract)

25) Evarts, E.V.: Pyramidal tract activity associated with a conditioned hand movement in the monkey. J Neurophysiol 29: 1011-1027, 1966.

26) Sasaki, K., Genba, H. and Hashimoto, H.: Premovement vs. pre-planned voluntary acts. Electroencephalogr Clin Neurophysiol 57: 356-371, 1984.

27) Tanji, J.: The supplementary motor area and voluntary movement. Advances in Neurolog Sciences 28: 67-76, 1984. (in Japanese, English abstract)

28) Roland, P.E., Larsen, B., Lassen, N.A. and Skinhoj, E.: Supplementary motor area and other cortical areas in organization of voluntary movements in man. J Neurophysiol 43: 118-136, 1980.

29) Roland, P.E., Skinhoj, E., Lassen, N.A. and Larsen, B.: Different cortical areas in man in organization of voluntary movements in extrapersonal space. $J$ Neurophysiol 43: 137-150, 1980.

30) Allen, G.I. and Tsukahara, N.: Cerebrocerebellar communication systems. Physiol Rev 54: 957-1006, 1974.

31) Fukamizu, K., Kodama, M., Moriya, Y. and Yokoyama, M.: The biting forces and the electromyographic analysises of the temporalis and the masseter muscles in the dentulous mandibular position. The Journal of the Japan Prosthodontic Society 16: 4653, 1972. (in Japanese, English abstract)

32) Yamashina, T., Fujii, H., Munehisa, N., Nagasawa, T. and Tsuru, H.: Effect of the oral sensory function on the activities of masticatory muscles. The Journal of the Japan Prosthodontic Society 21: 525-532, 1977. (in Japanese, English abstract) 